\title{
Clima social na família e estilos de pensar e criar ${ }^{1}$
}

\author{
Social climate in the family and styles \\ of thinking and creating
}

\author{
Fátima LOBO² \\ Mercês LOBO ${ }^{3}$
}

\section{Resumo}

A família constitui o núcleo dos laços ativos, na medida em que nela se criam as condições propícias ao desenvolvimento do indivíduo. Na sociedade atual, marcada pela emergência de novos modelos de família, de educação e de trabalho, o potencial cognitivo-criativo do sujeito tem-se afirmado como um fator diferenciador, nas diversas áreas de intervenção. Nesse contexto de emergência de novos paradigmas, esta investigação coloca a seguinte questão: a família contribui significativamente para o desenvolvimento das capacidades cognitivo-criativas? A título de hipótese, esta investigação assume que, se a família contribui para o desenvolvimento daquelas capacidades, então existe uma correlação significativa entre o clima familiar e os estilos de pensar e criar. O presente estudo, constituído por uma amostra de 312 estudantes portugueses do Ensino Superior da Licenciatura de Psicologia, teve como objeto de análise o clima social da família, a partir da Social Climate Scales Family - R Form. Simultaneamente, através da Escala de Estilos de Pensar e Criar de Wechsler, analisou-se o Estilo predominante de pensar e criar e, posteriormente, procedeu-se à verificação da existência de correlações significativas entre os dois constructos. Os resultados demonstraram correlações positivas entre o clima familiar e o estilo de pensar e criar.

Unitermos: Comportamento social. Criatividade. Relações familiares.

\begin{abstract}
The family constitutes the core of active bonds, as the conditions favoring the individual's development are created within it. In contemporary society marked by the emergence of new family, educational and work models, the cognitive-creative potential of the invididual has been affirmed as a differentiating factor in the diverse aeas of intervention. In this context of the emergence of new paradigms, this investigation asks the followng question: does the family contribute significantly to the development of cognitive-creative abilities? As its hypothesis this research assumes that if the family contributes to the development of these abilities, then there would be a significant correlation between the family climate and the styles of thinking and creating. The aim of this study, composed of a sample of 312 Portuguese students of the Graduate Courses of the Degree in Psychology, was to evaluate the family social environment by means of the Social Climate Scales of the Family - R Form. Simultaneously, using the Wechsler Styles of Thinking and Creating Scale, the predominant thinking and creative style was analyzed. After this the presence of significant correlations between the two constructs was verified. The resulted demonstrated positive correlations between social family climate and the styles of thinking and creating.
\end{abstract}

Uniterms: Social Behavior. Creativity. Family relations.

$\operatorname{crth}$

1 Apoio: Fundação para a Ciência e Tecnologia (PEst-OE/FIL/UI0683).

2 Universidade Católica Portuguesa, Centro Regional de Braga. Praça da Faculdade, 1, 4710-297, Braga, Portugal. Correspondência para/Correspondence to: F. LOBO. E-mail:<flobo@braga.ucp.pt>.

3 Universidade do Porto, Faculdade de Medicina. Porto, Portugal. 
A comunidade científica internacional, desde Guilford eTorrance, tem manifestado interesse crescente pela criatividade (Bruno-Faria, Veiga \& Macedo, 2008; Wechsler \& Nakano, 2002) como fator preditor de ajustamento social, de inovação e desenvolvimento, de promoção de equilíbrio sustentado, de aprendizagem, de gestão organizacional, de potencial competitivo, de desenvolvimento de organizações saudáveis, de resposta aos desequilíbrios, de desenvolvimento tecnológico, de renovação e melhoria incremental (Alencar, 1995; Amabile, 1996; Simon, 1988; Tang, 1998; Udwadia, 1990; Van Gungy, 1987; West, 2002) e de educação (Becker, et al., 2001; Fleith \& Alencar, 2008).

A Psicologia do Trabalho (Druker, 1998, 1999; Freire, 2000; Handy, 1999) e a Psicologia da Educação têm revelado maior apetência por essa área de investigação, perspectiva assumida pela União Europeia, que consagrou 2009 o Ano Europeu da Criatividade e da Inovação, reforçando o investimento europeu na educação, nas qualificações e na capacidade criativa (http:// www.create2009.europa.eu). Na mesma direção, as neurociências orientam as suas investigações no sentido de explicar os fenômenos da consciência (Damásio, 2000; Torrance, B. Taggart \& W. Taggart, 1984) e o potencial cerebral de mudança (Goleman, 2007).

Apesar do reconhecimento teórico da importância da família para o desenvolvimento individual e social (Bowlby, 2001, 2002, 2004; Dunst \& Bruder, 1999; Guralnick, 1997; Kellerhals, Ferreira \& Perrenoud, 2002), a criatividade tem sido remetida para os contextos formais de aprendizagem (Organização/Empresa, Escola e Sociedade). Essa teoria implícita explica, em certa medida, que à família tenha sido tradicionalmente atribuída a função de educador adaptativo e, mais recentemente, de suporte social (Alarcão, 2002; Carvalho, 1999; Coutinho, 2003; Menezes, 2007; Ornelas, 2008; Relvas \& Tribuna, 2002; Serrano, Pereira \& Carvalho, 2003; Silva \& Relvas, 2002; Sluzki, 2007; Sousa, Hespanha, Rodrigues \& Grilo, 2007; Vaz \& Relvas, 2002). A perspectiva ora desenvolvida considera a família como ambiente facilitador ou inibidor da criatividade e do estilo de pensar (Rogers, 1985; Wechsler, 2006).

As investigações sobre a criatividade apontam em vários sentidos: (i) poder preditor de mudança individual, organizacional e sociocomunitária (Alencar,
1995); (ii) necessidade de desenvolver o potencial criativo em razão da emergência de novos desafios nas áreas da educação, saúde, clínica, economia e cultura (Alencar, 1995; Getzels \& Jackson, 1962; Wechsler, 1998); (iii) mudança no paradigma epistemológico (Bono, 2000); (iv) desenvolvimento de instrumentos de medida (Torrance, 1990; Wechsler, 2006; Wechsler \& Nakano, 2002); e (v) relação entre a criatividade e as zonas corticais. Existe, portanto, forte consenso teórico-científico relativamente à importância da investigação e da implementação de estratégias de intervenção psicossociais na família, na escola, na empresa e na comunidade.

A década de setenta marcou, em termos de investigação teórico-experimental (Bandura, 1977; Craik, 1971, 1976, 1981), o início de um novo modelo epistemológico - comportamental e cognitivista (Gonçalves, 1994) - cujos pressupostos teóricos enfatizam a influência do meio, focando as variáveis ambientais. Outros autores consideram que o sujeito se autorregula cognitivamente, motivacionalmente e afetivamente (Bandura, 1994; Meichenbaum, 1977) e organiza as suas competências a partir da informação disponível e das suas capacidades para lidar com os problemas (self-efficacy).

Partindo desses quadros teóricos, qual a influência da família? A família representa $30 \%$ dos laços ativos (Ornelas, 2008; Wellman, 1992) e cria condições propícias ao desenvolvimento de certas tendências sentimentais e comportamentais. A família constitui, portanto, um elemento fundamental na totalidade das relações que o indivíduo estabelece. Sluzki (2007) é de opinião, na linha da Teoria de Campo de Lewin (Lewin, Lippit\&White, 1930; Lewin, 1965), que na família, nas amizades, nas relações laborais e nas relações comunitárias, estão incluídos todos os indivíduos com os quais os sujeitos interagem, e reconhece naquela as relações de maior proximidade, intimidade e potencial de intervenção.

A tradição iniciada por K. Lewin atribui à família o poder de contribuir para a estruturação emocional e cognitiva. A estrutura, o potencial de relação, de desenvolvimento e de estabilidade, induz estruturações emocionais e cognitivas em razão da situação psicológica e do significado que lhe é atribuído. O baixo potencial relacional de uma família, por hipótese, condiciona as conexões psicológicas e, por consequência, a atribuição de significado a sentimentos, comportamentos e pensamento, facilitadores ou inibidores da expressão 
ou produção criativa (Wechsler, 2006). Como sublinha Rogers (1985), as condições externas (a família, a escola, a empresa e a sociedade) e as condições internas ao indivíduo (hereditárias e características individuais da personalidade) são facilitadoras do desenvolvimento da criatividade construtiva.

Wechsler (2006) assume a origem hereditária e ambiental e a natureza compósita (emocional e cognitiva) da criatividade. Assume, também, a operatividade das emoções e dos processos cognitivos e que aquela se manifesta nas pessoas criativas pela: fluência, flexibilidade, ideias elaboradas, originalidade, sensibilidade interna e externa, fantasia, alta motivação, sentido de humor, impulsividade e espontaneidade, confiança em si mesmo, inconformismo, preferências por situações de risco, independência de julgamento, abertura a novas experiências, persistência, linguagem metafórica, capacidade de liderança, honestidade, otimismo, atitude visionária, tolerância às frustrações, sensibilidade ambiental, curiosidade, dinamismo e sentido de destino criativo, vinte e cinco características que serviram de base teórica à criação da Escala de Estilos de Pensar e criar.

O modelo de matriz humanista e transacional (Bruner, 1986; Maslow, 1970; Rogers, 1985; Wechsler, 2006) proposto por Wechsler assume a autorrealização como pressuposto transindividual e fundamento da lógica de sentido da realização do indivíduo e do seu potencial criativo, num contexto de construção dialogante entre a hereditariedade e o meio ambiente (familiar, educacional e social), regulado pelas características da personalidade individual. Tal pressuposto teórico vem de uma tradição que coloca a questão da família e da criatividade no contexto mais vasto da cultura (Bruner, 1986) e da internalização simbólica e criação de signos, ou seja, na "reconstrução interna de uma operação externa" (Vigotski, 2003, p.74), da reconstrução psicológica na base da qual está o poder de significar e simbolizar. Nesta perspectiva a criatividade é, também, a capacidade de inventar e usar "signos como meios auxiliares para solucionar um problema psicológico (lembrar, comparar coisas, relatar, escolher etc)" (Vigotski, 2003, p.70); de natureza individual (intrapessoal) e social (interpessoal). Nesse sentido, a criatividade construtiva, possibilita também o cumprimento de regulação homeostática da existência (Damásio, 2000) e a orientação e mobi- lização das potencialidades mentais para um fim que transcende a imediatez do dado - intencionalidade (Rogers, 1985).

A análise do clima social da família conforma-se às narrativas e modelos comunicacionais, aos significados partilhados pelas cognições humanas. A narrativa da identidade social da família é também uma metalinguagem cultural e educacional constituída e constituinte, e parte, geralmente, de uma visão a-negocial da cultura cuja centralidade é a transmissão de informação e o preenchimento com base em modelos de ensino e de aprendizagem demasiadamente influenciados pelo modelo hidráulico de Freud, pelo sistemismo estrutural de Piaget e pelo biologismo determinístico de Darwin (Bruner, 1986), embora a realidade se apresente mais complexa. A família, na sua qualidade ambiental primária, inibe ou desenvolve as estruturas (Bandura, 1978; Piaget, 1986) constitutivas (ou não) de desenvolvimento cognitivo-criativo. Inicia-se, também, na família o processo de interiorização. É no interior dela que a criança torna a realidade significativa para si e partilha significados do mundo no qual os outros já vivem; a partilha psicossocial de significados, por efeito da socialização primária, cria nexos temporais que se refletem na mútua identificação e partilha do objeto socializado. A identidade individual é simultaneamente objetivação de um mundo social específico e apropriação subjetivada (Berger \& Luckmann, 1999). Na família, locus de socialização primária, a criança interioriza e autoidentifica-se com papéis e atitudes sociais - controle, organização, conflito, coesão, autonomia ou outros (Moos \& Trickett, 1974) -, que ela progressivamente generaliza: "a formação na consciência, do outro generalizado, marca uma fase decisiva da socialização. Implica a interiorização da sociedade enquanto tal e da realidade objectiva nela estabelecida e, ao mesmo tempo, o estabelecimento subjectivo de uma identidade coerente e contínua" (Berger \& Luckmann, 1999, p.141).

Contudo, é através da família que a criança também se liberta. Alencar (1996) identifica cinco obstáculos categoriais à criatividade - estruturais, processuais, recursos, individuais e atitudinais. A família, à luz dessa tipologia, enquanto estrutura de suporte, obstaculiza ou promove.

Rogers (1985) reconhecia em 1952, na Universidade do Estado de Ohio, à família, à escola, às empresas 
e à sociedade em geral, o poder de formar indivíduos conformistas, estereotipados, em vez de pensadores livremente criadores e originais: "na vida familiar e individual, depara-se-nos o mesmo quadro. Na roupa que vestimos, na comida que comemos, nos livros que lemos e nas ideias que exprimimos, há uma forte tendência para o conformismo, para o estereotipado. Ser original, ser diferente, é considerado perigoso" (p.300).

A narrativa (Bohanek, Marin, Fivush \& Duke, 2004; Fivush, Bohanek, Robertson \& Duke, 2004) constitui a forma privilegiada de socialização primária e secundária: no espaço da família, da escola e da sociedade. E, nas diversas unidades de análise, a narrativa é dominada pela realidade psíquica (selfe mundo social) e pelo tipo básico de organização da linguagem - self transacional (Bruner, 1997). O self transacional, mais do que indicar a forma de funcionamento da mente, indica também "uma concepção sofisticada da mente de um parceiro" (Bruner, 1997, p.64), o sentido de grupo e de sustentabilidade do próprio grupo (self-mundo social), como socialização do self por processos de identificação e internalização (Bruner, 1997).

Nessa linha, este estudo propõe identificar o clima social das famílias dos estudantes da Licenciatura em Psicologia e seu estilo predominante de pensar e criar, bem como correlacioná-los entre si, no sentido de responder à questão: o clima familiar é preditor do estilo de pensar e criar?

\section{Método}

\section{Participantes}

Os dados foram coletados entre alunos de duas instituições de Ensino Superior. Os sujeitos da amostra ( $n=312$ ) fazem parte do corpo discente da Licenciatura em Psicologia de duas universidades portuguesas. Foram escolhidos aleatoriamente nos dois grupos representativos da comunidade acadêmica: Regime Geral e Regime Pós-Laboral. A amostra, inicialmente de 318 sujeitos, foi reduzida para 312 por exclusão de 6, cujos resultados da Escala de Desejabilidade Social se apresentaram superiores a 100, como prevê o protocolo 344 do instrumento (Wechsler, 2006).
A amostra foi composta por 216 mulheres (69\%) e 96 homens (31\%), 162 dos quais provenientes do meio rural e 150 do meio urbano. A maioria dos alunos avaliados frequentava o Regime Geral (288) e os restantes (24) o Regime Pós-Laboral. A amostra reflete a realidade sociológica das Licenciaturas de Psicologia, cuja população é maioritariamente feminina, proveniente dos meios rurais e matriculada no Regime Geral. Os estudantes apresentavam idade entre 18 e 63 anos, assim distribuídos: 93\% com idade entre 18 e 25 anos, 3\% com idade entre 26 e 35 anos, e 4\% com idade superior a 36 anos. A recolha da amostra foi efetuada em janeiro de 2009 na universidade do Norte de Portugal de alunos da licenciatura de Psicologia.

\section{Instrumentos}

Foram aplicados dois instrumentos: Social Climate Scales Family - R Form - (Moos \& Trickett, 1974) ea Escala de Estilos de Pensar e Criar (Wechsler, 2006). 0 primeiro foi objeto de tradução, tendo sido mantida integralmente a sua estrutura; as Escalas de Estilos de Pensar e Criar e Desejabilidade Social foram aplicadas na versão original (Wechsler, 2006). A Social Climate Scales Family - R Form é dicotômica, composta por 90 itens, agrupados em três dimensões e dez subescalas.

As subescalas avaliam: o grau de ajuda e de apoio entre os membros da família (coesão); a permissão e o incentivo pelos membros da família de atuar livremente e de expressar diretamente os seus sentimentos (expressividade); a expressão livre e aberta da cólera, da agressividade e do conflito (conflito); a segurança, autoconfiança e livre decisão dos membros da família (autonomia); a competição, a estruturação, a orientação das ações e das atividades na escola e no trabalho (procedimentos); o interesse pelas atividades políticas, sociais, intelectuais e culturais (intelectual-cultural); a participação em atividades sociais e recreativas (social-recreativo); a importância atribuída às práticas e valores éticos e religiosos (moralidade-religiosidade); a importância atribuída à organização, estrutura e planificação das atividades e responsabilidades da família (organização); e o grau em que a orientação da vida familiar segue regras e procedimentos estabelecidos (controle).

A dimensão relações, integrada pelas subescalas coesão, expressividade e conflito, avalia o grau de comu- 
nicação e livre expressão no interior da família e o grau de interação conflitual que a caracteriza. A dimensão Desenvolvimento, integrada pelas subescalas autonomia, procedimentos, intelectual-cultural, social-recreativo e moralidade-religiosidade, avalia a importância para a família de certos procedimentos de desenvolvimento pessoal que podem ser fomentados ou não através da vida em comum. A dimensão Estabilidade, integrada pelas subescalas organização e controle, avalia a estrutura e organização da família e o grau de controle que normalmente os membros da família exercem uns sobre os outros. Social Climate Scales Family - R Form (Moos \& Trickett, 1974) permite avaliar as características socioambientais, descrever as relações interpessoais entre os membros, e as relações e estruturas psicossociais mais relevantes (Tabela 1).
A Escala de Estilos de Pensar e Criar (Tabela 2), composta por 100 itens e seis modalidades de resposta - concordo totalmente, concordo, concordo parcialmente, discordo parcialmente, discordo e discordo totalmente -, identifica cinco estilos de pensar e criar: estilo cauteloso reflexivo, estilo inconformista transformador, estilo lógico objetivo, estilo emocional intuitivo e estilo relacional divergente. Esses estilos permitem interpretar os estilos principais e secundários, bem como definir as características cognitivas e afetivas do sujeito analisado e os estilos de interação preferenciais com os quais pode rentabilizar o potencial de inovação, objetividade e consenso, ampliar a ponderação das ações, aumentar a noção de risco, ponderação e gestão das emoções. A Escala de Estilos de Pensar e Criar avalia as

Tabela 1. Análise de regressão linear para os Estilos de Pensar e Criar, tomando como variáveis preditoras as subescalas da Social Climate Scales Family - R Form. Portugal (2009).

\begin{tabular}{|c|c|c|c|c|c|c|c|}
\hline Variáveis dependentes & Subescalas/variáveis independentes & B & SE & Beta & $\mathrm{T}$ & Sig. & $\mathrm{N}$ \\
\hline \multirow[t]{4}{*}{ Estilo lógico objetivo } & Coesão & 0,907 & 0,215 & 0,299 & 4,218 & 0,000 & 312 \\
\hline & Procedimentos & 0,953 & 0,213 & 0,248 & 4,479 & 0,000 & 312 \\
\hline & Moralidade-religiosidade & 0,819 & 0,158 & 0,299 & 5,186 & 0,000 & 312 \\
\hline & Organização & $-0,821$ & 0,229 & $-0,241$ & $-3,578$ & 0,000 & 312 \\
\hline \multirow[t]{2}{*}{ Estilo cauteloso reflexivo } & Intelectual-cultural & $-2,310$ & 0,532 & $-2,590$ & $-4,338$ & 0,000 & 312 \\
\hline & Organização & $-3,095$ & 0,794 & $-0,270$ & $-3,898$ & 0,000 & 312 \\
\hline \multirow[t]{3}{*}{ Estilo inconformista transformador } & Conflito & $-2,695$ & 0,811 & $-0,185$ & $-3,324$ & 0,001 & 312 \\
\hline & Procedimentos & 2,226 & 0,498 & 0,240 & 4,469 & 0,000 & 312 \\
\hline & Intelectual-cultural & 2,842 & 0,362 & 0,427 & 7,841 & 0,000 & 312 \\
\hline \multirow[t]{2}{*}{ Estilo emocional intuitivo } & Procedimentos & 0,878 & 0,153 & 0,307 & 5,737 & 0,000 & 312 \\
\hline & Intelectual-cultural & 0,620 & 0,111 & 0,314 & 5,598 & 0,000 & 312 \\
\hline \multirow[t]{5}{*}{ Estilo relacional divergente } & Expressividade & 0,858 & 0,225 & 0,236 & 3,823 & 0,000 & 312 \\
\hline & Conflito & $-0,707$ & 0,234 & $-0,168$ & $-3,015$ & 0,003 & 312 \\
\hline & Intelectual-cultural & 0,714 & 0,117 & 0,356 & 6,081 & 0,000 & 312 \\
\hline & Social-recreativa & $-0,476$ & 0,165 & $-0,187$ & $-2,876$ & 0,004 & 312 \\
\hline & Moralidade-religiosidade & 0,376 & 0,121 & 0,182 & 3,119 & 0,002 & 312 \\
\hline
\end{tabular}

Sig*: Significância do coeficiente $p<0,005$.

Tabela 2. Análise de regressão linear para a Desejabilidade Social, tomando como variáveis preditoras as subescalas The Social Climate Scales Family - R Form. Portugal (2009).

\begin{tabular}{|c|c|c|c|c|c|c|c|}
\hline Variável dependente & Subescalas/variável independentes & B & SE & Beta & $\mathrm{T}$ & Sig." & $\mathrm{N}$ \\
\hline \multirow{6}{*}{ Desejabilidade social } & Coesão & $-1,062$ & 0,368 & $-0,197$ & $-2,885$ & 0,004 & 312 \\
\hline & Expressividade & $-1,769$ & 0,504 & $-0,207$ & $-3,512$ & 0,001 & 312 \\
\hline & Conflito & 2,043 & 0,520 & 0,207 & 3,004 & 0,000 & 312 \\
\hline & Procedimentos & 1,167 & 0,364 & 0,171 & 3,204 & 0,002 & 312 \\
\hline & Moralidade-religiosidade & $-1,170$ & 0,271 & 0,241 & 4,323 & 0,000 & 312 \\
\hline & Controle & $-1,520$ & 0,472 & $-0,199$ & $-3,220$ & 0,001 & 312 \\
\hline
\end{tabular}

Sig*: Significância do coeficiente $p<0,005$. 
formas preferenciais de pensar e comportar, abarcando, simultaneamente, características cognitivas e de personalidade que condicionam a percepção da realidade (Tabela 2).

Os Estilos de Pensar e Criar assentam-se no pressuposto de que o pensamento e a criação são expressão das habilidades cognitivas e das características da personalidade individual, mediadas pelos ambientes, acontecimentos, pessoas ou circunstâncias da vida, e de que o indivíduo tende para a autorrealização - motivação primária (Rogers, 1985; Wechsler, 2006). Os resultados individuais são pontuados seguindo o protocolo de correção e as tabelas para conversão do resultado bruto em resultado padronizado (Wechsler, 2006).

\section{Procedimentos}

Os Comitês de Ética das instituições objeto deste estudo foram esclarecidos sobre a investigação e consentiram que se procedesse à seleção de uma amostra aleatória e que os dois instrumentos fossem aplicados de forma coletiva durante o período de aula. Igualmente, os alunos assinaram o Termo de Consentimento Livre e Esclarecido, depois de devidamente informados e esclarecidos, conforme orientação da Federação Europeia de Associações de Psicólogos e do Código Deontológico dos Psicólogos Portugueses, elaborado pela Ordem dos Psicólogos Portugueses, criada em 2008, pela Lei n57/2008, de 4 de setembro de 2008.

\section{Resultados e Discussão}

A análise da consistência interna da Escala de Clima Social da Família apresentou alfa de Cronbach igual a 0,70, resultado que indica variabilidade nas respostas dos inquiridos. A correlação item total revelou índices mais elevados, indicador de menor variabilidade nos seguintes itens: $1,12,15,26,31,32,45,47,48,49,51$, 55, 58, 59, 62, 71, 75, 79, 82 e 90, correspondente respectivamente às seguintes falas: "Na minha família ajudamo-nos e apoiamo-nos realmente uns aos outros; Em casa falamos abertamente do que nos parece ou queremos; Para a minha família é muito importante triunfar na vida; Na minha familia é muito importante aprender algo de novo e diferente; Na minha familia há um forte sentido de união; Na minha casa comentamos os nossos problemas pessoais; Esforçamo-nos por fazer as coisas cada vez melhor; Na minha casa todos temos uma ou duas atividades de que gostamos; Na minha família temos ideias muito precisas sobre o que está bem ou mal; Na minha familia mudamos de opinião com frequência; As pessoas da minha família apoiam-se de verdade umas às outras; Em casa, preocupamo-nos pouco com o sucesso no trabalho e as classificações escolares; Acreditamos que há certas coisas sobre as quais énecessário ter fé; Em casa preocupamo-nos que os nossos quartos fiquem arrumados; Na minha casa as questões de pagamento e dinheiro decidem-se abertamente; Realmente damo-nos bem uns com os outros; Primeiro o trabalho, depois a diversão, éo lema da família; Na minha família o dinheiro não se administra com muito cuidado; Na minha casa expressamos as nossas opiniões de modo frequente e espontâneo; Na minha família cada um orienta-se por si". Os valores obtidos nestes itens indicam peso elevado em três subescalas: coesão; expressividade e organização.

Os valores mais baixos referem-se às subescalas: Conflito e Moralidade-Religiosidade, respectivamente nos itens 43, 53, 73, 83 e 18, 78 e 88, assim expressos: "Na minha família criticamo-nos frequentemente uns ao outros; Na minha família, porvezes, lutamos fisicamente; Os membros da minha família estão zangados uns com os outros; Na minha família acreditamos que não se consegue muito elevando a voz; Na minha casa rezamos em familia; Na minha casa ler a Bíblia é algo muito importante; Na minha familia acreditamos que aquele que comete uma falta terá o seu castigo".

Para efeito de análise iniciou-se pela consideração, para cada indivíduo, do estilo principal e do estilo secundário com valores médios ou elevados, após correção e interpretação dos resultados de acordo com os procedimentos prescritos, tanto no nível da pontuação como da tabela de conversão de resultados brutos em resultados padronizados em função da idade e do gênero (Wechsler, 2006). Seguindo esse critério, os seguintes resultados referentes à Escala de Estilos de Pensar e Criar: 198 indivíduos (63,0\%) com estilo lógico objetivo; 60 indivíduos (19,0\%) com estilo relacional divergente; 36 indivíduos $(11,5 \%$, com estilo emocional intuitivo; 12 indivíduos (3,8\%) com estilo inconformado transformador e 6 indivíduos $(1,9 \%)$ com estilo cauteloso reflexivo. Verifica-se, pois, forte preponderância do estilo lógico objetivo no que concerne ao estilo principal, e forte incidência no estilo relacional divergente, no que 
se refere ao estilo secundário. Os resultados da escala de desejabilidade social apresentaram-se ajustados, exceto seis indivíduos com valores superiores a 100, que foram excluídos da amostra.

No sentido de identificar a importância das subescalas Social Climate Scales Family - R Form na explicação dos Estilos de Pensar e Criar, procedeu-se à análise de regressão linear, método Enter, tomando como preditoras as dez subescalas (Tabela 1).

A análise de regressão linear para o estilo lógico objetivo apresentou os escores mais elevados, podendo ser considerado esse o estilo predominante da amostra. Sua significância no teste F apresentou-se inferior a 0,005, identificando quatro variáveis preditoras: coesão, procedimentos, moralidade-religiosidade e organização. Nesse sentido, os resultados indicam que o sujeito lógico objetivo, com resultados médios ou acima da média, caracteriza-se pela reflexão, controle emocional, baixo grau de improvisação, dificuldade em interagir com pessoas pouco objetivas e gosto por situações práticas e estruturadas; e provém de uma estrutura familiar caracterizada pela ajuda e apoio de seus membros, competitiva e orientada para as ações, que atribui importância aos valores éticos e religiosos e que planifica as atividades e responsabilidades familiares.

O estilo cauteloso reflexivo, o menos representativo na amostra estudantil, é explicado pelas subescalas organização e intelectual-cultural. A prudência, a sistematização e a assertividade são características cognitivas preditas pelo interesse pelas atividades políticas, sociais, intelectuais e culturais e pela importância atribuída à organização, estrutura e planificação das atividades e responsabilidades da família. Os resultados indicam que a estruturação e planificação das atividades familiares, associadas a interesses familiares diversos, tais como política, sociedade e cultura, predizem sujeitos prudentes, metódicos, sistemáticos, críticos, avaliadores e reflexivos.

As subescalas conflito, intelectual-cultural e procedimentos são preditoras do estilo inconformista transformador; assim, famílias competitivas, que expressam livre e abertamente cólera e agressividade, estruturadas, orientadas para as ações e as atividades escolares e laborais, associadas a interesses diversos, como as atividades políticas, sociais, intelectuais e culturais, predizem indivíduos questionadores, dinâmicos e sonhadores, com potencial de liderança, níveis elevados de confian- ça, preferência pela execução de várias tarefas simultaneamente, níveis elevados de sociabilidade, gosto pela resolução de problemas de forma incomum e sentido de missão criativa.

As subescalas procedimentos e intelectual-cultural predizem o estilo emocional intuitivo, caracterizado pela emocionalidade, intuição, imaginação, fantasia, impulsividade e curiosidade. Assim, famílias com interesses diversos, competitivas, estruturadas e orientadoras das ações, predizem sujeitos caracterizados pelo predomínio das emoções, da imaginação e da fantasia, impulsivos, com gosto pelo risco e facilidade em expressar sentimentos.

As subescalas expressividade, conflito, intelectual-cultural, social-recreativa e moralidade-religiosidade são preditoras do estilo racional divergente. Nesse sentido, famílias cujo ambiente familiar cultiva e incentiva os seus membros a atuar e expressar-se livremente, a participar de atividades sociais e recreativas, com interesses diversificados e sentido prático, ético e religioso, são preditivas de sujeitos com facilidade de liderança, direcionados para objetivos a longo prazo e abertos a novas ideias.

As subescalas organização e intelectual-cultural são preditoras do estilo cauteloso. Assim, ambientes familiares caracterizados pela organização, estruturação e planificação das atividades e responsabilidades familiares e com interesses culturais sociais e políticos diversificados predizem indivíduos prudentes, metódicos, sistemáticos, reflexivos e pouco assertivos.

Procedeu-se, posteriormente, à segunda análise de regressão linear para a desejabilidade social, no sentido de identificar o poder preditivo das dez subescalas e das três dimensões The Social Climate Scales Family - $R$ Form (Tabela 2), sendo apresentadas somente aquelas que apontam significância estatística.

As subescalas Coesão, Expressividade, Conflito, Moralidade-Religiosidade e Controle são preditoras da Desejabilidade Social; as restantes subescalas - Autonomia, Intelectual-Cultural, Sócio-Recreativo e Organização - não apresentaram valores significativos, motivo pelo qual não predizem a desejabilidade social.

As subescalas explicam o Estilo Inconformista Transformador, o Estilo Emocional Intuitivo, o Estilo Racional Divergente e a Desejabilidade Social (Tabela 3). Os estilos Lógico Objetivo e Cauteloso Reflexivo não apresentaram resultados significativos. As dimensões 
Relações e Desenvolvimento predizem os Estilos Inconformista Transformador e Emocional Intuitivo, significando que os fatores comunicacionais e de desenvolvimento pessoal influenciam os estilos de pensar e criar caracterizados pela flexibilidade, criatividade, imaginação, fantasia, curiosidade inovação, sociabilidade, multiplicidade de funções e competências. As dimensões Relações e Estabilidade predizem a Desejabilidade Social, e a dimensão Desenvolvimento, o Estilo Relacional Divergente. A dimensão Desenvolvimento é preditora de maior número de Estilos de Pensar e Criar, e a Estabilidade é preditora apenas da Desejabilidade Social.

Procedeu-se à análise de regressão linear para as três dimensões do clima e assumiram-se as variáveis gênero, idade e naturalidade (meio rural e urbano) como suas preditoras (Tabela 4). A variável idade não apresentou valores significativos, enquanto a naturalidade e o gênero explicam o grau de comunicação, expressão e interação no interior da família (relações) e o grau de controle entre seus membros (estabilidade). Verifica-se também que idade, gênero e naturalidade não explicam a dimensão desenvolvimento.

Levando em consideração o estilo mais representativo da amostra (Estilo Lógico Objetivo), o menos representativo (Estilo Inconformista Transformador) e a Escala de Desejabilidade Social, este estudo procedeu à análise de regressão linear, tomando as três variáveis sociodemográficas (idade, gênero e naturalidade) como suas preditoras (Tabela 5). A idade, a naturalidade - meio rural / meio urbano - e o gênero são preditores do Estilo Lógico Objetivo; por sua vez, a naturalidade prediz, igualmente, o Estilo Inconformista Transformado e a Desejabilidade Social.

A amostra de 312 estudantes de Psicologia apresentou resultados que majoritariamente (63\%) se identificam com o Estilo Lógico Objetivo. Os estudantes apresentaram valores médios e/ou acima da média, o que permite concluir que eles se caracterizam pela prudência, reflexão e ordem, embora demonstrem baixa assertividade, gosto pela rotina e baixo potencial de liderança. Provêm de famílias com médio ou elevado grau de ajuda e apoio entre seus membros, que oferecem orientação das atividades escolares, atribuem importância às práticas e valores ético e religiosos e valorizam a organização, estrutura e planificação das atividades familiares.

A investigação empírica permite concluir, também, que o Clima familiar é preditor dos Estilos de Pensar e Criar e da Desejabilidade Social. As subescalas com maior poder preditivo são Intelectual-Cultural, Procedimentos e Moralidade-Religiosidade.

Tabela 3. Análise de regressão linear para os Estilos de Pensar e Criar, tomando como variáveis preditoras as três dimensões (Relações, Desenvolvimento e Estabilidade) The Social Climate Scales Family - R Form. Portugal (2009).

\begin{tabular}{|c|c|c|c|c|c|c|c|}
\hline Variável dependente & Dimensões/variáveis dependentes & B & SE & Beta & $\mathrm{T}$ & Sig." & $\mathrm{N}$ \\
\hline \multirow[t]{2}{*}{ Estilo inconformista transformador } & Relações & $-1,607$ & 0,280 & 0,325 & $-5,745$ & 0,000 & 312 \\
\hline & Desenvolvimento & 0,951 & 0,153 & 0,345 & 6,226 & 0,000 & 312 \\
\hline \multirow[t]{2}{*}{ Estilo emocional intuitivo } & Relações & $-0,468$ & 0,087 & $-0,309$ & $-5,357$ & 0,000 & 312 \\
\hline & Desenvolvimento & 0,197 & 0,047 & 0,238 & 4,212 & 0,000 & 312 \\
\hline Estilo racional divergente & Desenvolvimento & 0,237 & 0,049 & 0,283 & 4,877 & 0,000 & 312 \\
\hline \multirow[t]{2}{*}{ Escala de desejabilidade social } & Relações & $-0,966$ & 0,210 & $-0,268$ & $-4,600$ & 0,000 & 312 \\
\hline & Estabilidade & $-0,757$ & 0,238 & $-0,181$ & $-3,183$ & 0,002 & 312 \\
\hline
\end{tabular}

Sig*: Significância do coeficiente $p<0,005$.

Tabela 4. Análise de regressão linear para as dimensões Social Climate Scales Family - R Form, considerando sexo, idade e naturalidade como variáveis preditoras. Portugal (2009).

\begin{tabular}{|c|c|c|c|c|c|c|c|}
\hline Variável dependente & Dimensões/variáveis independentes & B & SE & Beta & T & Sig." & N \\
\hline Relações & Naturalidade & 1,053 & 0,299 & 0,199 & 3,525 & 0,000 & 310 \\
\hline \multirow[t]{2}{*}{ Estabilidade } & Sexo & $-1,767$ & 0,263 & $-0,359$ & $-6,713$ & 0,000 & 310 \\
\hline & Naturalidade & 0,740 & 0,244 & 0,162 & 3,030 & 0,003 & 310 \\
\hline
\end{tabular}

Sig*: Significância do coeficiente $p<0,005$. 
A subescala intelectual-cultural prediz os estilos cauteloso reflexivo, inconformista transformador, emocional intuitivo e relacional divergente. Significa que o grau de participação grupal da família em atividades de natureza política, social, intelectual e cultural influencia o estilo cognitivo de seus membros, predispondo-os para a reflexão e o pensamento crítico, para a avaliação e a sistematicidade, para o questionamento, o dinamismo, a espontaneidade e o otimismo, para a sociabilidade, a empatia e o potencial de liderança, para a criatividade e a curiosidade, para a abertura a novas situações e ao sentido de risco.

Por sua vez, famílias que privilegiem a competição e a estruturação e orientação das ações e das atividades na escola e no trabalho (Procedimentos) predizem estilos cognitivos caracterizados pela lógica, racionalidade e pragmatismo, pelo gosto por regras e persistência nas ações, com sentido de missão e facilidade para liderar grupos, sujeitos autoconfiantes, flexíveis, orientados para objetivos a longo prazo e abertos a novas ideias.

As famílias que atribuem importância às práticas religiosas e aos valores éticos (moralidade-religiosidade) predizem estilos cognitivos caracterizados pela pragmaticidade e racionalidade, com preferência por soluções conhecidas, gosto por regras, dificuldade de trabalhar em grupo e controle das emoções e sentimentos.

A subescala conflito e a dimensão desenvolvimento predizem o estilo relacional divergente, o estilo inconformista transformador e a desejabilidade social. Assim, as famílias caracterizadas pelo conflito predizem estilos cognitivos caracterizados pela rigidez nas ações, pela dificuldade de trabalhar em grupo e em liderar pessoas, pelo baixo nível de sociabilidade, baixa confian- ça, baixo nível de fantasia e emoção, elevada pragmaticidade e preferência por situações conhecidas.

As famílias que atribuem importância a certos procedimentos no desenvolvimento pessoal e fomentam certas práticas, principalmente culturais, recreativas e religiosas, predizem estilos cognitivos caracterizados pelo questionamento, facilidade em liderar pessoas, otimistas, flexíveis, imaginativas, que fazem uso de linguagem metafórica e analógica e apresentam facilidade em liderar grupos.

As subescalas coesão, expressividade, sócio-recreativo e organização são preditoras, respectivamente, do estilo lógico objetivo e desejabilidade social; relacional divergente e desejabilidade social; relacional divergente; lógico objetivo e cauteloso reflexivo. Assim, famílias coesas predizem o estilo lógico objetivo, parecendo indicar um conceito de coesão familiar caracterizado pela falta de comunicação interpessoal, pelo controle das emoções, pela previsão e pelo uso de regras. Famílias expressivas e sócio-recreativas, ou seja aquelas que expressam livre e diretamente os seus sentimentos e participam de atividades sociais de natureza diversa, por sua vez, são preditoras de estilos cognitivos, flexíveis, que atendem às opiniões alheias e são abertas a novas ideias e novas situações. Famílias organizadas, que planificam as suas atividades e responsabilidades são preditoras de estilo predominantemente avaliador e sistemático.

\section{Considerações Finais}

Os resultados revelam, portanto, forte relação entre o Clima Social na Família e os Estilos de Pensar e Criar, assumindo as dimensões Relações e Desen-

Tabela 5. Análise de regressão linear para os Estilos Principal e Secundário e Desejabilidade Social, considerando sexo, idade e naturalidade como variáveis preditoras. Portugal (2009).

\begin{tabular}{|c|c|c|c|c|c|c|c|}
\hline Variável dependente & Dimensões/variáveis independentes & B & SE & Beta & $\mathrm{T}$ & Sig. ${ }^{*}$ & $\mathrm{~N}$ \\
\hline \multirow[t]{3}{*}{ Estilo principal } & Idade & $-3,646$ & 0,707 & $-0,282$ & $-5,157$ & 0,000 & 312 \\
\hline & Sexo & $-0,303$ & 0,108 & $-0,154$ & $-2,806$ & 0,005 & 310 \\
\hline & Naturalidade & 0,448 & 0,100 & 0,247 & 4,495 & 0,000 & 310 \\
\hline Estilo secundário & Naturalidade & $-0,646$ & 0,125 & $-0,283$ & $-5,152$ & 0,000 & 310 \\
\hline Desejabilidade social & Naturalidade & $-3,591$ & 1,051 & $-0,189$ & $-3,418$ & 0,001 & 312 \\
\hline
\end{tabular}

Sig*: Significância do coeficiente $p<0,005$. 
volvimento maior poder preditivo. O presente estudo permite sugerir algumas conclusões e, embora não existam outras investigações que tenham aplicado os dois instrumentos com os quais fosse possível verificar e contrastar os resultados obtidos, é possível concluir que o clima familiar se relaciona significativamente com o estilo cognitivo de pensar e criar.

A elevada importância das dimensões Procedimentos, Moralidade-Religiosidade, Organização, Intelectual-Cultural e Conflito fornecem indicadores precisos sobre a importância que a família deve atribuir ao sucesso acadêmico e profissional, ao desempenho e gestão dos recursos intelectuais e econômicos, aos atos festivos e sua simbologia, aos valores éticos, religiosos e morais, à planificação das atividades em família, à higiene, à ordem, à pontualidade, às opiniões, à definição de tarefas, à administração dos recursos, à atenção dispensada à análise da realidade política e cultural, à frequência a conferências, palestras e concertos, à abertura à novidade, à elevação cultural do ambiente familiar, à leitura e à gestão das emoções.

Os resultados desta investigação indicam claramente o papel e a importância da família no processo de desenvolvimento de seus membros e, consequentemente, a sua responsabilidade social e pedagógica.

Esta pesquisa constitui a primeira abordagem com o cruzamento destes dois instrumentos - Escala de Estilos de Pensar e Criar e Social Climate Scales Family - R Form - e fornece elementos auxiliares na área da Psicologia da Educação, contribuindo para melhor compreensão das relações interpessoais prevalentes no contexto escolar. No que diz respeito à área da Psicologia da Família, a pesquisa aponta a importância desta para a estruturação cognitiva do indivíduo, podendo fornecer subsídios a projetos comunitários de prevenção a transtornos mentais menores, na sociedade em geral e na comunidade educativa em particular.

\section{Referências}

Alarcão, M. (2002). Novas formas de família, novas formas de terapia. In A. P. Relvas \& M. Alarcão (Coord.), Novas formas de família (pp.13-51). Slavador: Quarteto Editora.

Alencar, E. M. L. S. (1995). Desenvolvendo a criatividade nas organizações: o desafio da inovação. Revista de Administração de Empresas, 35 (6), 6-11.

Alencar, E. M. L. S. (1996). A gerência da criatividade. São 350 Paulo: Makron Books.
Amabile, T. M. (1996). Creativity and innovation in organizations. Harvard Business School, 5, 1-15.

Bandura, A. (1977). Social learning theory. Englwood Cliff: Prentice Hall.

Bandura, A. (1978). The self system in reciprocal determinism. American Psychology, 33 (4), 344-358.

Bandura, A. (1994). Self-efficacy. In V. S. Ramachaudran (Ed.), Encyclopedia of human behaviour (Vol. 4, pp.71-81). New York: Academic Press.

Becker, M. A. A., Roazzi, A.; Madeira, M. J. P., Arend, I.; Schneider, D., \& Wainberg, L., et al. (2001). Estudo exploratório da conceitualização de criatividade em estudantes universitário. Psicologia: Reflexão e Crítica, 14 (3), 571-579. Recuperado em janeiro 2, 2009, disponível em <http:// www.scielo.br/scileo.php?pid=SO102-797220010003 00012\&script=sci_arttext $>$.

Berger, P. L., \& Luckmann, T. (1999). A construção social da realidade. Petrópolis: Vozes.

Bohanek, J. G., Marin, K. A., Fivush, R., \& Duke, M. P. (2004). Family narrative interaction and children's self-understanding. Family Processes, 45 (1), 39-54.

Bono, E. (2000). Criatividade como recurso (Ed. Especial, pp.66-73). São Paulo: HSH Management.

Bowlby, J. (2001). Formação e rompimento dos laços afectivos. São Paulo: Martins Fontes.

Bowlby, J. (2002). Apego a natureza do vínculo: apego e perda. São Paulo: Martins Fontes.

Bowlby, J. (2004). Angústia e raiva: apego e perda (Vol. 2). São Paulo: Martins Fontes.

Bruner, J. (1986). Actual minds, possible worlds. Cambridge: Harvard University Press.

Bruner, J. (1997). Actos de significação. Porto Alegre: Artes Médicas.

Bruno-Faria, M. F., Veiga, H. M. S., \& Macedo L. F. (2008). Criatividade nas organizações: análise da produção científica nacional em periódicos e livros de Administração e Psicologia. RPOT, 8 (1), 142-163.

Carvalho, J. N. (1999). Relações afectivas e saúde mental. Salvador: Quarteto.

Craik, K. H. (1971). Environmental psychology. Annual Review, 24, 403-422.

Craik, K. H. (1976). The personality research paradigm in environmental Psychology. In S. Wapner, S. B. Cohen \& B. Kaplan (Eds.), Experiencing the environment (pp.55-79). New York: Plenum Press.

Craik, K. H. (1981). Environmental assessment and situational analysis. In D. Magnusson (Ed.), Toward a psychology of situations: an interactional perspective (pp.275-295). New Jersey: Lawrewnce Erlbaum.

Coutinho, M. T. (2003). Formação parental: avaliação do impacte na família. Psicologia, 17 (1), 227-244.

Damásio, A. R. (2000). O sentimento de si: o corpo, a emoção e a neurobiologia da consciência. Lisboa: Europa América.

Druker, P. (1998). A organização do futuro.Lisboa: EuropaAmérica. 
Druker, P. (1999). Sobre a profissão de gestão. Lisboa: Europa-América.

Dunst, C. J., \& Bruder, M. B. (1999). Family and community activity settings, natural learning environments, and children's learning opportunities. Children's Learning Opportunities Report, 1 (2), 37-48.

Fivush, R., Bohanek, J., Robertson, R., \& Duke, M. (2004). Family narratives and the development of childreen's well-being. In M. W. Pratt \& B. E. Fiese (Eds.), Family stories and the lifecourse: across time and generations (pp. 55-76). New York: Rodutlege.

Fleith, D. S., \& Alencar, E. M. L. S. (2008). Características personológicas e factores ambientais relacionados com a criatividade do aluno do ensino fundamental. Avaliação Psicológica, 7 (1), 35-44. Recuperado em novembro 12 , 2008, disponível em <http://pepsic.bvs-psi.org.br/scielo. php?script=sci_arttext\&pid=s1677-047120080001 > .

Freire, A. (2000). Inovação: novos produtos, serviços enegócios para Portugal. Lisboa: Verbo.

Getzels, J. M., \& Jackson. (1962). Creativity and intelligence exploration with gifted students. New York: John Wiley.

Goleman, D. (2007). Emoções destrutivas e como dominá-las. (3a ed.). Lisboa: Temas e Debates.

Gonçalves, O. (1994). Terapias cognitivas: teorias e práticas. Porto: Afrontamento.

Guralnick, M. (1997). Second generation research in the field of early intervention. In M. Guralnick (Ed.), The effectiveness of early intervention (pp.5-21). Seattle: University of Washington.

Handy, C. (1999). Deuses da gestão ou a era da mudança. Lisboa: Cetop. Recuperado em fevereiro 9, 2009, disponível em <http://www.create2009.europa.eu>.

Kellerhals, J., Ferreira, C., \& Perrenoud, D. (2002). Linguagens do parentesco: lógicas de construção identitária. Análise Social, 37 (162), 545-567.

Lewin, K. (1965). Teoria de campo em ciência social. São Paulo: Universidade de São Paulo.

Lewin, K., Lippit, R., \&White, R.K. (1930). Patterns of aggressive behaviour in experimentally created social climates. Journal Social Psychology, 10 (2), 271-299.

Maslow, A. H. (1970). Motivation and personality. New York: Harper \& Row.

Meichenbaum, D. (1977). Cognitive behavior modification. New York: Plenum.

Menezes, I. (2007). Intervenção comunitárial: uma perspectiva psicológica. Porto: Livpsic.

Moos, R. H., \& Trickett, E. J. (1974, 1981). A social climate scale. Palo Alto: Consulting Psychology Press, Inc.

Ornelas, J. (2008). Psicologia comunitária. Lisboa: Fim de Século.

Piaget, J. (1986). O nascimento da inteligência na criança (Biblioteca de Pedagogia, Psicologia e Psicanálise). Porto Alegre: Dom Quixote.

Relvas, A. P., \& Tribuna, F. (2002). Família de acolhimento e vinculação na adolescência. In A. P. Relvas \& M. Alarcão (Coords.), Novas formas de família (pp.53-113). Salvador: Quarteto.
Rogers, C. R. (1985). Tornar-se pessoa (7a ed.). Lisboa: Moraes.

Serrano, A. M., Pereira, A. P., \& Carvalho, M. L. (2003). Oportunidades de aprendizagem para a criança nos seus contextos de vida: família e comunidade. Psicologia, 17 (1), 65-80.

Silva, M. H., \& Relvas, A., P. (2002). Casal, casamento e união de facto. In A. P. Relvas \& M. Alarcão (Coords.), Novas formas de família (pp.189-239). Salvador: Quarteto.

Simon, H. A. (1988). A creativity and motivation: a response to Csikszentmihalyi. New ldeas in Psychology, 6 (2), 177-181.

Sluzki, C. (2007). Rede social e perspectiva familiar sistémica. In L. Fernandes \& M. R. Santos (Coord.), Terapia familiar, redes e poética social (pp.97-108). Lisboa: Climepsi.

Sousa, L., Hespanha, P., Rodrigues, S., \& Grilo, P. (2007). Famílias pobres: desafios à intervenção social. Lisboa: Climepsi.

Tang, H. K. (1998). An integrative model of innovation in organizations. Technovation, 18 (5), 297-309.

Torrance, E. P. (1990). Torrancetests of creative thinking: figural forms A and B. Benseville: Scholastic Testing Service.

Torrance, E. P., Taggart, B., \& Taggart, W. (1984). Human information processing survey-HIP. Illinois: Scholastic Testing Survey.

Udwadia, F. E. (1990). Creativity and innovation in organizations: two models and managerial implications. Technological Forecasting and Social Change, 38 (1), 65-80.

van Gungy, A. (1987). Organizational creativity and innovation. In S. G. Isaksen (Ed.), Frontiers of creativity research (pp.358-379). Buffalo: Bearly.

Vaz, C. P., \& Relvas, A. P. (2002). Monoparentalidade: uma família à parte ou parte de uma família? In A. P. Relvas \& M. Alarcão (Coords.), Novas formas de família (pp.245-295). Salvador: Quarteto.

Vigotski, L. S. (2003). A formação social da mente. São Paulo: Martins Fontes.

Wechsler, S. M. (1998). Avaliação multidimensional da criatividade: uma realidade necessária. Psicologia Escolar e Educacional, 2 (2), 89-99. Recuperado em janeiro 8, 2009, disponível em <http://scielo.bvs-psi.org.br/scielo.php? pid=S1413-85571998000200003\&script0sci>.

Wechsler, S. M. (2006). Estilos de pensar e criar. Campinas: PUC-Campinas.

Wechsler, S. M., \& Nakano, T. C. (2002). Caminhos para a avaliação da criatividade: perspectiva brasileira. In Instituto Brasileiro de Avaliação Psicológica. Temas em avaliação psicológica (pp.103-115). Campinas: Impressão Digital do Brasil.

Wellman, B. (1992). Which types of ties and networks provide what kinds of social support? Advances in Group Processes, 9, 207-235.

West, M. A. (2002). Sparkling fountains or stagnant ponds: an integrative model of creativity and innovation implementation in work groups. Applied Psychology: an International Review, 5 (3), 355-387.

Recebido em: 21/12/2009

Versão final reapresentada em: 17/10/2011

Aprovado em: 10/2/2012 
